\title{
RISK MANAGEMENT APPLIED TO ELECTRICAL DISTRIBUTION SYSTEMS
}

\author{
Carl Johan WALLNERSTRÖM \\ KTH - Sweden \\ cjw@kth.se
}

\begin{abstract}
This paper summarizes results from a research project investigating risk management applied to electrical distribution systems (EDS) in Sweden. New incentives have motivated the distribution system operators (DSOs) to consider more comprehensive analysis methods. The project focuses on investigating long term consequences of different project-and maintenance plans. This paper shortly describes related research, incentives, results from an application study and future work. The main conclusion is that there is a trend that DSOs use more complex risk management approaches as a result of new incentives.
\end{abstract}

\section{INTRODUCTION}

No technical systems are $100 \%$ reliable. Accordingly, risk of failures with the consequence of customer outages in electrical distribution systems (EDS) is unavoidable. There is not economical motivated, or possible, to work towards maximal reliability. Hence, good balance between the aim of risk reduction and the investment cost is important. Our society has become more dependent on reliable electricity distribution and the demand of cost efficiency has increased since new incentives have appeared followed by the world wide tendency of de-regulations [1]. To meet current and future requirement, new methods and tools to perform risk analyses are needed. In Sweden, development of analysis methods is for example forced by a new law of mandatory risk and vulnerability analysis [2].

A crucial issue when developing new analysis methods is the balance between complexity and usefulness. A new method must give higher profit than the resources it demands. Experiences from both the industry and from research projects are valuable to coordinate. To utilize industry experience in an academic project, collaboration with a Scandinavian DSO has been initiated as an application study. The first step of the application study has recently been presented in [3]. This paper summarizes results and present ideas of future work of this project.

\section{DEFINITIONS}

- Reliability is "the ability of a component or system to perform required functions under stated conditions for a stated period of time [4]".

- Redundancy is "more than one independent opportunity for a piece of equipment to carry out a desired function [5]"; active redundancy when one or more reserve items operate parallel; passive redundancy when one or more reserve items are in cold standby [6].

\author{
Lina BERTLING \\ Chalmers Technical University- Sweden \\ lina.bertling@chalmers.se
}

- $\quad$ Failure is "the termination of the ability of a component or system to perform a required function [4]".

- Customer outage is when the electrical supply is interrupted $\geq 3$ minutes (due to earlier Swedish regulation [7]) and affects one or more customers.

- System Average Interruption Duration Index [8] $(\mathrm{SAIDI})=\frac{\sum_{i}\left(U_{i} * N_{i}\right)}{\sum_{i}\left(N_{i}\right)}$ [hours and minutes/year], where $U_{i}$ [hours/year] is the sum of the length of every customer outage affecting Load Point $\mathrm{i}\left(\mathrm{LP}_{\mathrm{i}}\right)$ during one year and $\mathrm{N}_{\mathrm{i}}$ is number of customers at the $\mathrm{LP}_{\mathrm{i}}$.

- Expected Energy at Risk (EEAR) [MWh] is the expected amount of demanded energy that cannot be served without overloading transmission equipment [9].

- The "N-1 criterion" is defined by "that a power system can withstand the loss of an individual principal component (production unit, line, transformer etc.) [5]"

\section{RELATED RESEARCH}

Reliability Centered Maintenance (RCM) is an advanced form of preventive maintenance planning, first developed by the aircraft industry [10]. High costs related to maintenance, combined with extreme demand on safety, motivated the development of a more systematic maintenance planning. RCM has spread to other industries. At the Royal Institute of Technology (KTH) there is ongoing research of developing RCM since about ten years [11]. The approach is to develop a more analytical RCMmethod, adjusted to the electrical industry, referred to as RCAM (Reliability-Centered Asset Management) [12], [13]. Within this research, component reliability modeling [14], reliability analysis methods and component priority methods [15] are developed [11]. A new Swedish law of annual mandatory risk and vulnerability analysis [2] has resulted in the start of new research projects on risk management. One example is "the risk analysis program" within the organization Elforsk [16], where three industry projects and two licentiate thesis [1], [17] recently have been completed.

\section{CURRENT AND FUTURE INCENTIVES}

A law, introduced in Sweden 2006, dictates that every DSO annually have to report result from a risk- and vulnerability analysis regarding the reliability of the EDS [2]. The risk analysis has to include an action plan of how the reliability shall be improved. However, new circumstances since the 
re-regulation, such as new techniques, new laws, and the climate debate have increased the incentives of performing good risk management regardless of the obligation. In Sweden, the customers are compensated with $12.5 \%$ of the annual tariff after 12 hours of customer outage (minimum 100 Euros) [18]. This compensation increases with the customer outage time, to a maximum of $300 \%$ of the annual tariff. Furthermore, a new law states a functional requirement on EDS [2] where no customer outages longer than 24 hours are allowed from 2011. Consequently, 12 and 24 hours are important limits for the DSOs considering the planning and the risk management in Sweden.

The regulation of EDS-tariffs using the Network Performance Assessment Model (NPAM) [19] [20] has been criticized by stakeholders with legal processes. In late 2008 the parties made an agreement and in January 2009 the regulator decided to abandon the NPAM [21]. Sweden will, as the last country in Europe, implement a new ex-ante regulation from 2012 [21]. EU-laws force Sweden to go from an ex-post to an ex-ante regulation. Ex-ante is when the regulator judges the level of customer tariffs before they finally are settled and applied by the DSO. The new regulation will probably continue to focus on similar objectives as the NPAM such as cost efficiency, reliability and customer values. Hence, the regulation will give incentives to more knowledge based planning and well performed risk management of the EDS.

\section{RISK MANAGEMENT OF EDS}

Risks associated with EDS could typically be divided into the following categories:

- Risks of breaking environmental or safety laws.

- Risks of customer outages which give repair costs, but also costs related to customer outages.

- Risks of other events which only result in repair costs.

- Administrative risks.

This project mainly focuses on category 2 [1]. A risk is often defined as the probability of an event multiplied by its negative consequences. Consequences could in this case be expressed in terms of customer outages, event as a possible scenario including this consequence and probability as a quantitative estimated failure frequency. Compared with other technical systems, EDS have special characteristics to consider when developing new methods, e.g. [1]:

- An event could affect a greater area of the EDS since failures have to be disconnected according to safety aspect for humans and equipments.

- Some components are significantly exposed and vulnerable to weather events. This gives dependent effects of when failure occurs which has to be handled.

- EDS are operated as regulated monopolies. The incentives of investments depend on the regulation.

- EDS are connected to and dependent of the transmission system, supply points and load points.

\section{CURRENT RISK MANAGEMENT AT A DSO}

\section{Introduction to the application study}

An ongoing application study is included in the project. This is collaboration with Fortum Distribution, a DSO operating in the northern part of Europe. This paper summarizes results from this study. Some results have previously been presented in [3], which include a description of current risk management principles, on how incentives have affected this DSO and some evaluations. This application example was chosen because Fortum Distribution recently has introduced more structured work and quantitative and knowledge based analysis methods in the project planning processes and the risk management. From 2006 to 2011, Fortum Distribution runs a large project referred to as the "Reliability Program". The goal is to costefficiently reduce SAIDI to $\leq 1$ hour for rural and semi-rural areas by 2011. This corresponds to more than a $50 \%$ reduction from historical SAIDI values of about 2-4 hrs. Most likely the reliability program had been designed differently and implemented less rapidly without incentives such as compensation for outages longer than 12 hour [18].

In Sweden, EDS could be divided into local (0.4-24 kV) and regional $(>24 \mathrm{kV})$ EDS. There are large differences between these systems, both in terms of operation, but also in the risk management and network planning. At regional EDS the focus is on individual components (e.g. power transformers) and on the N-1 criterion, complemented by probabilistic measures such as EEAR while the risk management at local EDS more focuses on reliability (e.g. assessment of SAIDI) and volume (number of customers). Local EDS use historical outages data as an important input for project selection whereas regional EDS have more of a forward-looking approach, i.e., what can happen in the future if the system remains in today's configuration? Local EDS are generally operated radially in rural areas which can include passive redundancy using normally open disconnectors (redundancy more generally used in urban areas) while regional EDS often operates with active redundancy. Depending on the voltage level, Fortum Distribution applies three levels of risk assessment policies:

1. Local EDS, low voltage (LV) $[0.4 \mathrm{kV}]$.

2. Local EDS, medium voltage (MV) [1.0-24 kV].

3. Regional EDS [ $>24 \mathrm{kV}]$.

\section{Local Electrical Distribution Systems}

LV EDS are not a part the overall risk management; secondary substations included. Failures at this level seldom lead to any larger interruptions affecting many customers. The contribution to the total SAIDI is less than $15 \%$. Investments are made when required, e.g. in case of wornout equipment, corrective maintenance and connections of new customers. This policy divides more economic resources to other parts of the EDS, in line with the overall strategy of maximizing the cost effectiveness. 
The MV level of EDS contributes to $\sim 85 \%$ of SAIDI estimated by Fortum. Hence, the risk management focuses on reliability, mainly to handle weather related outages. A large share of the total investment budget is annually directed towards reinvestments on this voltage level. The goal is to decrease SAIDI and the overall strategy is to cost efficient replace weather vulnerable lines (focus on snow and wind). A range of different solutions are used. The risk analysis method at this level could roughly be divided into six steps which are further described in [3]:

1. Information collection, e.g. historical outage data.

2. List of lines with poor performance.

3. Producing overall plans.

4. Project proposals.

5. Project prioritizing using business ratios.

6. Project performance.

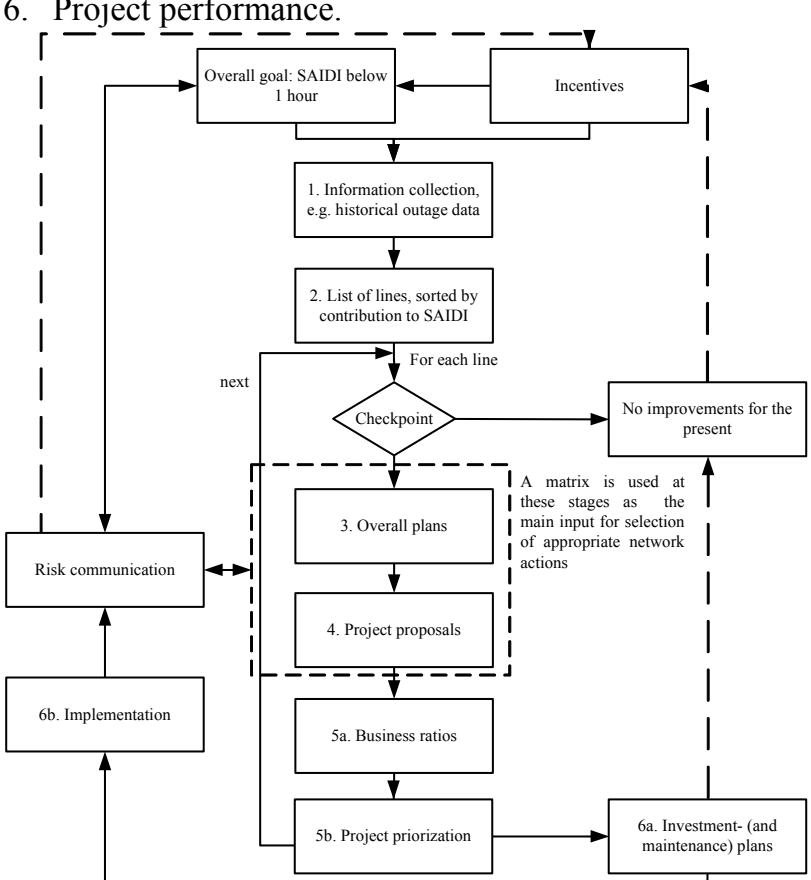

Figure 1 Project planning \& risk management (1-24 kV)

\section{Regional Electrical Distribution Systems}

Regional EDS are not as vulnerable for snow and wind, such as the local EDS. The contribution to SAIDI is relatively low. The risk management instead focuses on the risk of extensive and long outages exceeding 12 hours. The probability of customer outages caused by this voltage level is small, but the consequence can be significant. 12 and 24 hours maximum interruptions are important target levels, mainly driven by current legislation. The risk analysis method at this level could roughly be divided into six steps which are further described in [3]:

1. Identification of main risks

2. Sorting out due to the "N-1" criterion.

3. Sorting out due to expected duration and loss of power.

4. Risk matrices.

5. Preventive planning and project proposals.

6. Project performance.

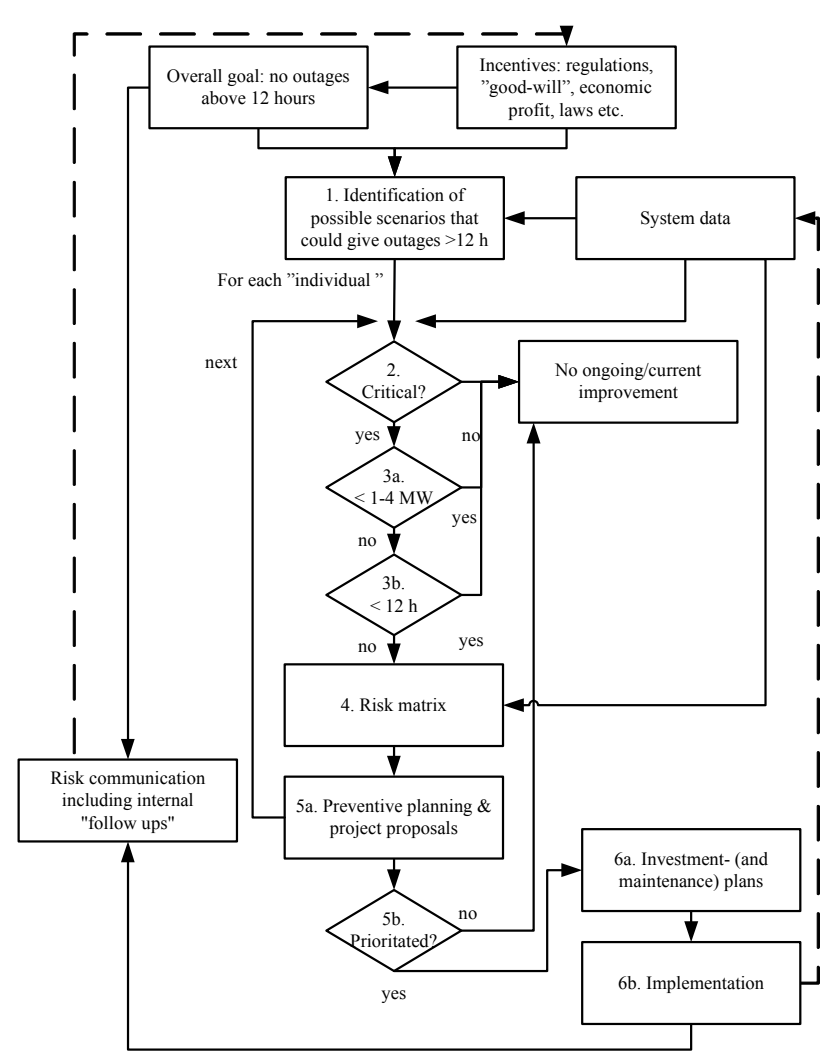

Figure 2 Project planning \& risk management $(>24 \mathrm{kV})$

\section{Risk Communication}

Risk communication is an important part of the risk management. Three categories of risk communication:

1. The regulating authority: Annual risk and vulnerability analysis. Other kinds of information sharing such as failure statistics are also regulated [10].

2. Internal: The projects have to be motivated due to the decreased risks and to the cost effectiveness. Goodwill effects must sometimes internally be estimated and included to make single projects profitability.

3. Customers: Important, both during the project planning and afterwards to increase the acceptance and goodwill.

\section{Evaluation of Current Risk and Planning Polices}

At MV EDS, a reliability analysis is performed. The reliability model only estimates consequences for one line at a time without the system perspective. A consequence of this simplification is that the model ignores dependencies in the EDS and that the method is not applicable to urban EDS. Hence, there is a potential to develop the reliability analysis methods. Local- and regional EDS have different methods motivated by the operation and the categories of risks. At local EDS, the focus is concentrated to few areas which are the most important according to reliability statistics. These risks are however most obvious, but in the future these risks are mitigated due to the current strategy and new risks could instead appear (e.g. risks associated with underground cables). Consequently, the current focus area is good, but a wider risk focus should be considered. 


\section{CONCLUSION}

This project has shown that there are strong incentives to develop more quantitative methods of risk management and network planning applied to EDS. Moreover, these are motivated by new identified incentives. However, differences between voltage levels in EDS are significant and justified. The paper has evaluated and presented current risk management at a DSO.

\section{FUTURE WORK}

This project aims to complement ongoing activities in the RCAM research group by investigate risks of introducing RCAM-plans. The aim is also to generally investigate longterm impact of planning methods. The future work can be summarized in two points:

- Continue the case study.

- Estimate consequences/risks of introducing maintenance- and investment plans. This includes proposals of how to manage these consequences/risks.

Risks of introducing investment and maintenance plans are estimated by comparing different scenarios. The total cost is will be calculated by LCC-analyses while risks will be qualitative identified. Proposals should be made on how identified risks could be managed. Sensitivity analyses will be done to deal with uncertainties in assumptions. Maintenance and investment planning will be analyzed separately by different methods (1-2) and then compiled and analyzed from an overall perspective (3).

1. Maintenance Plans: Several of the analysis steps will be made in consultation with DSOs to strive for realism:

a. Select test systems to use (e.g. RBTS).

b. Put up scenarios for maintenance plans.

c. Collect input data (based on e.g. statistics) and make models (e.g. how the failure rate varies due to maintenance actions).

d. Calculate the results of different scenarios, analytically and/or with simulations.

e. Do cost analyses (LCC) and identify risks.

f. Compare the different scenarios and do sensitivity analyses.

2. Investment: comparing the impact of the introduction of the current investment planning by comparing the current planning methods with earlier methods for similar examples. Estimate LCC costs of each case and identify potential risks through qualitative analysis.

3. Summary: Gather, analyze and make conclusions. Make an approach to manage identified risks.

\section{Acknowledgments}

The authors gratefully acknowledge Jörgen Hasselström and Per Bengtsson, Fortum Distribution, Karlstad, Sweden, for the contribution of knowledge from interviews and help with the collection of input data.

\section{REFERENCES}

[1] C.J. Wallnerström., 2008, On Risk Management of Electrical Distribution Systems and the Impact of Regulations, Licentiate Thesis, KTH, Sweden

[2] The Swedish Law for the Electric Power System, Chapter 4, ("Ellagen"), including updates until 2008

[3] C.J. Wallnerström., J. Hasselström, P. Bengtsson, L. Bertling, 2008, Review of the Risk Management at a Distribution System Operator, PMAPS, Puerto Rico

[4] IEEE Std 493-2007, 2007, "IEEE Gold Book"

[5] Nordel, 2007, Nordic Grid Code

[6] A. Hoyland, M. Rausand, 2004, System reliability theory - models and statistical methods

[7] M. Larsson, 2005, The Network Performance Assessment Model - A new framework of regulating the Electricity Network Companies, Licentiate Thesis, KTH, EE, KTH, Stockholm, Sweden

[8] R. Billinton, R. Allan, 1996, Reliability Evaluation of Power Systems, New York, US (2nd Edition, Plenum)

[9] H. Lee Willis, 2002, Spatial Electric Load Forecasting, ISBN 0824708407, Second Edition

[10] J. Moubray, 1991, Reliability-centred Maintenance, Butterworth-Heinermann, Oxford

[11] L. Bertling, 2008, The RCAM research group - history and status, KTH, School of Electrical Engineering

[12] L. Bertling, 2002, Reliability-Centered Maintenance for Electric Power Distribution Systems, Doctoral thesis, KTH, Stockholm, Sweden

[13] L. Bertling, R. Eriksson, R. Allan, 2005, A reliabilitycentred asset maintenance method for assessing the impact of maintenance in power distribution systems, IEEE Transactions on Power Systems

[14] T. Lindquist, 2008, On reliability and maintenance modelling of ageing equipment in electrical power systems, Doctoral Thesis, KTH, Stockholm, Sweden

[15] P. Hilber, V. Miranda, M. Matos, L. Bertling, 2007, Multiobjective Optimization Applied to Maintenance Policy for Electrical Networks, IEEE Transactions on Power Systems, Volume 22, No. 4

[16] Elforsk, http://www.elforsk.se

[17] K. Alvehag, 2008, Impact of Dependencies in Risk Assessments of Power Distribution Systems, Licentiate Thesis, KTH, Stockholm, Sweden

[18] J. Setréus, C. J. Wallnerström, L. Bertling, 2007, A Comparative Study of Regulation Policies for Interruption of Supply of Electrical Distribution Systems in Sweden and UK, CIRED, Vienna

[19] C. J. Wallnerström, L. Bertling, 2008, Investigation of the Robustness of the Swedish Network Performance Assessment Model, IEEE Transactions on Power Systems, Volume 23, No. 2

[20] C. J. Wallnerström, L. Bertling, 2007, A Sensitivity Study of the Swedish Network Performance Assessment Model Investigating the Effects of Changes in Input Data, , CIRED, Vienna

[21] Svensk Energi, http://www.svenskenergi.se 